\title{
OTIMIZAÇÃO DA PURIFICAÇÃO DO INIBIDOR DE PROTEASE DE CHENOPODIUM QUINOA COM AQUECIMENTO
}

\author{
Cipriano, N. M. Jr. ${ }^{*}$, Tonelli, F.C. P. ${ }^{2}$.; Gonçaves, D.B. ${ }^{1}$; Silva, J.A. ${ }^{1}$; \\ Granjeiro P.A. ${ }^{1}$ \\ ${ }^{1}$ Curso de Bioquímica, Universidade Federal de São João Del-Rei, Divinópolis/MG \\ ${ }^{2}$ Curso de Farmácia, Universidade Federal de São João Del-Rei, Divinópolis/MG \\ *e-mail: nciprianojr@gmail.com
}

\section{Resumo}

Os inibidores de proteases são uma classe de proteínas envolvidas em muitos processos fisiológicos celulares. Portanto, um desequilíbrio no balanço de proteases e seus inibidores caracterizam muitos processos patológicos humanos, como o câncer e a inflamação. Sendo seu estudo alvo para pesquisas de novos fármacos. Chenopodium quinoa, pseudoceral nativo dos Andes, apresenta sementes ricas em proteínas e seu consumo tem aumentado em países em desenvolvimento. Relatos na literatura demonstram no mínimo 3 passos cromatográficos necessários para a sua completa purificação. Estudos de estabilidade demonstram que os inibidores de proteases frequentemente mantém atividade em altas temperaturas. $\mathrm{O}$ objetivo desse trabalho foi desenvolver um protocolo mais econômico e eficaz para purificação de inibidores de protease, utilizando o aquecimento a $100^{\circ} \mathrm{C}$ por $5 \mathrm{~min}$. O sobrenadante do extrato bruto de C. quinoa foi testado quanto a sua estabilidade térmica em diferentes temperaturas de 37 à $100^{\circ} \mathrm{C}$ por 5 min e não apresentou perda de atividade antitríptica na temperatura de $90^{\circ} \mathrm{C}$. Amostras de extrato bruto pré-aquecidas em $90^{\circ} \mathrm{C}$ e aplicadas em coluna de cromatografia de exclusão molecular do tipo Sephadex G50 apresentou cromatograma com menor intensidade de picos proteicos. Em seguida, o pool de proteínas com atividade antitríptica foi centrifugado e o sobrenadante submetido à Eletroforese SDS-PAGE nas condições desnaturantes e confirmaram menor teor de proteínas contaminantes. $\mathrm{O}$ resultado da aplicação na coluna G50 após o aquecimento à $90^{\circ} \mathrm{C}$ indicou que grande parte das proteínas contaminantes foram eliminadas no aquecimento por 
não serem termoestáveis. Os resultados obtidos permitiram a formulação de um novo protocolo de purificação, acentuadamente mais eficiente e diminuindo os custos do processo.

Palavras chaves: Chenopodium quinoa, purificação de proteína, estabilidade térmica. 